\title{
Agroecologia em dinâmicas de agricultura sustentável de Apodi-RN
}

\author{
Agroecology dynamics in sustainable agriculture Apodi-RN \\ Ana Beatriz Alves de Araújo', Érika Benjamim², Carlos Enrique de M. Jerônimo³ \\ 1. Mestranda da Universidade Federal Rural do Semi-Árido. \\ 2, Especialista em Direito e Processo do Trabalho, mestranda pela Universidade Federal Rural do Semi-Árido, professora universitária. \\ ${ }^{3}$ Doutorado em Eng. Química. Professor da Universidade Potiguar.
}

\begin{abstract}
Resumo
O acesso a políticas, a habilidade de organização coletiva e a inclusão em mercados continuamente são entraves para o segmento da agricultura familiar. Desafiando estes problemas, um grupo de mulheres do assentamento de reforma agrária Mulunguzinho, de Mossoró (RN), iniciou no ano de 1999 um procedimento de produção agrícola fundamentado em princípios da agroecologia, e, de forma precursora na região, buscou integrar sua produção ao consumo solidário. Essa ação, a qual foi norteada e acompanhada por ONG's, embolsou confiabilidade da sociedade a ponto de se ampliar e hoje se localizar presente em dez municípios do Rio Grande do Norte através da Rede Xique Xique. A metodologia consistiu em aplicar questionários em 169 unidades produtivas em 21 comunidades rurais, com a finalidade de identificar técnicas e conhecimentos introduzidos pelos agricultores familiares vinculados à Rede Xique Xique. As principais variáveis analisadas foram: uso de insumos químicos e se realiza praticas agroecológicas. Constatou-se, portanto, que Apodi se configura uma experiência de diversificação da agricultura familiar da Rede Xique Xique e possui um elevado potencial de expansão das práticas agroecológicas. Porém, suas estruturas produtivas encontram-se frágeis devido à ausência de assistência técnica. Isso torna necessária a ação de políticas capazes de ajudar os agricultores familiares a superar desafios, pois mesmo com limitações essa experiência já contribui para a transição do sistema tradicional para sistemas agroecológicos.
\end{abstract}

Palavras-chave: Agroecologia, Sustentabilidade e Rede Xique-Xiqu

\begin{abstract}
The Access policies the ability to organize collectively and inclusion in markets are continuously barriers to the segment of the family farm. Challenging these problems, a group of women in agrarian reform settlement Mulunguzinho of Mossoró (RN), initiated in 1999 a procedure for agricultural production based on principles of agroecology, and so forerunner in the region, sought to integrate its production to solidary consumption. This action, which was guided and supported by NGOs, pocketed reliability of the company about to expand and today we find this in ten municipalities in Rio Grande do Norte by Network Xique Xique. The methodology consisted of applying questionnaires in 169 production facilities in 21 rural communities in order to identify skills and knowledge introduced by farmers related to Network Chique Chique. The main variables analyzed were: the use of chemical inputs and performs agroecological practices. It was found, therefore, that Apodi experience configuring a diversified family farming Network Xique Xique and has a high potential for expansion of agroecological practices. However, its production structures are weak due to absence of technical assistance. This necessitates the action policies that help farmers to overcome challenges, because even with limitations that experience already contributes to the transition from traditional to agroecosystems. Keywords: Agroecology, sustainable and Xique-Xique Net.
\end{abstract}




\section{INTRODUÇÃO}

Para a agricultura familiar, o acesso a políticas, o reconhecimento da capacidade de organização coletiva dos atores e a inserção em mercados com o domínio de habilidades de comercialização sempre representaram grandes obstáculos. Para superar estes obstáculos, algumas das estratégias deste segmento têm sido notadamente duas: a primeira é a alteração de suas práticas agrícolas por meio da reconversão do formato técnico e produtivo dos sistemas de produção, notando-se um crescente interesse pela produção agroecológica, ou de baixo uso de insumos agroquímicos. E a segunda é a de se organizar econômica e socialmente para se tornar cada vez mais capaz de gerar oportunidades de reunir os mecanismos necessários para de forma competitiva se inserir nos mercados.

Em várias regiões do Brasil, já não é desprezível o número de iniciativas onde agricultores programam mudanças na base técnica de produção, desenvolvendo práticas agroecológicas. Essas práticas de produção tendem a tornar as propriedades menos dependentes de recursos externos (agroquímicos, técnicas, etc.) nocivos a terra e ao seu equilíbrio natural, recursos estes na maioria das vezes mobilizados por oligopólios. Com isso a agricultores familiares têm realizado uma transição produtiva e se inserido em um mercado em crescente expansão, ou seja, o mercado consumidor de produtos diferenciados pela sua origem e cuidados com os recursos naturais e respeito à biodiversidade.

Por outro lado, surgem estratégias que se destacam como alternativa na criação e ampliação de oportunidades, e que cada vez mais vêm ganhando força, estimulando formas mais eficientes e justas de organização da produção, do trabalho e do acesso a mercados através da Economia Solidária. É neste contexto que emergem experiências de transição da base técnica convencional para práticas agroecológicas, as quais têm definido dinâmicas diversificadas e sustentáveis de agricultura familiar. Essas experiências têm se mostrado adequadas para a análise do desenvolvimento rural na interpretação da experiência de Economia Solidária. A Rede Xique Xique, no estado do Rio Grande do Norte, se apresenta como uma experiência de diversificação da agricultura familiar que reúne tanto a prática de uma agricultura sustentável, esta baseada nos princípios da agroecologia, como a ação coletiva via organizações da Economia Solidária.
A partir da discussão interna da rede sobre o que agroecologia, o pressuposto deste resumo é o de que as práticas de produção empreendidas pela Rede Xique Xique ainda é insuficiente, e não atendem em sua plenitude aos princípios básicos da noção de agroecologia. Neste sentido, passa a ser necessário verificar o processo de produção e analisar de forma detalhada as práticas agroecológicas introduzidas pela Rede Xique Xique em Apodi (RN).

\section{REFERENCIAL TEÓRICO}

De acordo com GLIESSMAN (2009), a abordagem ecológica dos sistemas agrícolas proporciona um ambiente favorável para o conhecimento e desenvolvimento de métodos necessários para desenvolver uma agricultura produtiva, sustentável e economicamente viável. A sustentabilidade de um sistema agrícola é alcançada através de técnicas e práticas alternativas baseadas em um conhecimento aprofundado dos processos ecológicos, através do qual, é possível promover mudanças socioeconômicas capazes de dar sustentabilidade a todo encadeamento produtivo. Além disso, tal abordagem aplicada de forma ampla possibilita o conhecimento para avaliar e examinar o desenvolvimento histórico de atividades agrícolas desenvolvidas em cada região, criando uma base de conhecimento capaz de nortear as práticas mais sustentáveis e adaptadas a cada sistema de cultivo ou a cada região agrícola.

De acordo com ALTIERI (2009) praticar a agricultura sustentável, ou a agroecologia exige do agricultor a superação de alguns desafios que estarão presentes no seu dia a dia. Os principais desafios elencados por ALTIERI (2009) são: primeiro o desafio ambiental, sendo a agricultura uma atividade causadora de impactos ambientais e que necessita de insumos externos para que ela possa se tornar uma agricultura sustentável. Para este desafio se faz necessário um manejo diferenciado dos recursos que englobam todo o processo de produção.

O segundo desafio é o econômico, o qual consiste em adotar sistemas de produção e de cultivo que minimizem perdas e desperdícios como também que apresentem produtividade compatível com os investimentos feitos. O terceiro desafio é o social, o qual consiste em adotar sistemas de produção que assegurem geração de renda para o trabalhador rural e que este tenha condições dignas de trabalho, com remuneração compatível 
com sua importância no processo de produção. O quarto desafio é o territorial, pois este busca a viabilização de uma eficaz integração agrícola com o meio rural, por meio da pluriatividade e da multifuncionalidade desses espaços. E, por fim, o quinto desafio que é o tecnológico, o qual busca introduzir as tecnologias voltadas para a agricultura que seja menos nocivas ao meio ambiente, já que na agricultura grande parte de suas atividades depende de tecnologias, que na sua maioria são causadoras de impactos ambientais.

A dinâmica da agricultura sustentável, conforme ALTIERI (2009) exige um manejo adequado das práticas com o rigor não apenas no nível da unidade de produção. Exige também em nível distrital, regional, nacional e mesmo internacional, já que, os princípios do manejo agroecológico incluem prospecção de elementos essenciais como água e nutrientes das bacias hidrográficas, manejo desse fluxo de nutrientes na propriedade, manejo para os consumidores no entorno da propriedade, uso ponderado dos recursos hídricos, aumento da biodiversidade e uso das fontes renováveis de energia.

Uma diferença básica e de fácil sustentável, ou agroecológica, é que na agricultura convencional são usadas medidas drásticas para controlar pragas especificas e deficiências no solo, já que eles procuram uma produção alta e com resultados em curto prazo. Já a agricultura sustentável, geralmente, refere-se a um modo de fazer agricultura que busca assegurar produtividades sustentadas ao longo prazo, e que preserve os meios pelo qual estão cercados, através de práticas de manejo ecologicamente seguro, de um modo que não cause prejuízos ou danos desnecessários e irreparáveis ao meio ambiente. (PRETTY, 1995 apud ALTIERE, 2009).

De modo geral, a agricultura convencional com a ajuda das inovações tecnológicas, e desenvolvimento de novas variedades de plantas, o uso intensivo de fertilizantes e agrotóxico, como também o crescimento de grandes infraestruturas de irrigação, tem conseguido manter o rendimento na produção de grãos. Contudo, esse sistema de produção retira excessivamente e degrada os recursos naturais dos quais a agricultura depende como solo, reservas de água e a diversidade genética natural, vale ressaltar ainda, que a agricultura convencional tornou-se dependente do uso dos combustíveis fósseis não renováveis, que para GLIESSMAN (2009), esse modo de produção mostra-se insustentável. A sustentabilidade só poderá ser alcançada através de práticas agrícolas alternativas, que se mostram como uma forma de manejar adequadamente os recursos naturais e que visa proporcionar equilíbrio econômico, social, ambiental e territorial.

Esse modelo da economia solidária opera de maneira diferente do modelo competitivo de mercado, pois valoriza a ação coletiva para o alcance de objetivos comuns, não visando apenas resultados econômicos imediatos, como o lucro. Sua lógica vai além dos fatores meramente econômicos (sem jamais desprezá-los ou subjugá-los) e considera fatores não econômicos, a exemplo da ética, da autonomia e da diversidade, onde, como lembra PLOEG (2008), a cooperação e a inovação acontecem e se tornam elementos indispensáveis.

Entretanto, no modelo de economia solidária são notadas duas perspectivas de compreensão. A primeira perspectiva está associada à revolução social e tem a defesa no Brasil por SINGER (2000) o qual defende implantes socialistas no interior do capitalismo visando à sua destruição. A segunda, defendida por FRANÇA FILHO \& LAVILLE (2004), reforça a possibilidade da convivência da economia solidária junto ao sistema capitalista e defende o pluralismo econômico, onde os empreendimentos econômicos coletivos atuam no campo da produção e da comercialização. E é com esta segunda perspectiva que este trabalho interage, tendo em vista a análise da comercialização solidária da Rede Xique Xique.

Para SINGER (2002), a economia solidária se configura um "outro tipo modo de produção", outra maneira de "fazer as coisas", em que a base dos seus princípios é a propriedade coletiva e o direito à liberdade individual. Segundo o autor, a desigualdade representa uma consequência negativa produzida e reproduzida pelo sistema capitalista, sendo uma construção humana fruto das relações sociais e econômicas e não um processo espontâneo e natural, sendo a desigualdade algo que se pode prever e evitar. Do mesmo modo, conforme PLOEG (2008) são a competição e a seleção que constroem um ambiente onde apenas poucos sobrevivem e que, sem uma regulação cria um ambiente institucional favorável ao que WILLIAMSON (2000) classifica como oportunismos ${ }^{l}$, estes frutos da trapaça, da desonestidade, deserção, etc.

\footnotetext{
1 Williamson (2000) chama a atenção para as instituições formais (leis, constituições, contratos, etc.) como forma destas dotarem os atores de mais capacidade para lidar com distorções como oportunismo e deserção. A existência destas distorções nas estruturas institucionais remete ao conflito, onde se torna necessária a constante luta entre atores e organizações nos mais diferentes níveis, com a finalidade de diminuir a assimetria e realizar alterações e ajustes tendo em vista promover a mudança e a evolução institucional.
} 
e, assim como a desigualdade também representam uma construção da própria sociedade e não um processo natural e de geração espontânea.

Para PLOEG (2008), a construção dessa identidade, dos mecanismos de regulação, dos mercados locais e da diversidade regional é resultado da interação entre a ação econômica, que se traduz na produção material, e a ação social que se traduz na reprodução das relações entre a unidade produtiva e as formas de criação e acesso aos mercados. Isso representa o que NUNES (2009) define como processos de desenvolvimento rural, onde a ação dos agricultores familiares acontece de forma endógena, no interior da propriedade, possibilitando o surgimento da inovação e a emergência de dinâmicas regionais de desenvolvimento rural. Para NUNES (2009), essa dinâmica regional de desenvolvimento rural se dá pela interação entre o ambiente institucional (região ou território) no nível macro e arranjos institucionais (grupos, cooperativas, unidades familiares, etc.) construídos no nível local, micro, onde estes últimos formatam sistemas produtivos da agricultura familiar. O desempenho dos arranjos institucionais, segundo NUNES (2009), é resultado dos níveis de cooperação e de confiança entre os atores econômicos e sociais na condução das suas atividades e, especialmente, das suas estratégias de organização.

Para uma análise da dinâmica regional do desenvolvimento rural tomamos por base neste artigo à relação entre o ambiente institucional dos territórios e os arranjos locais formados pelas organizações que constituem a Rede Xique Xique no Rio Grande do Norte. Os arranjos locais que formam a Rede Xique Xique buscam aplicar os princípios fundamentais da economia solidária e empreender processos de desenvolvimento rural. Estes arranjos institucionais são formados e organizados por agricultores familiares que constroem os processos internos de desenvolvimento rural e definem padrões em dinâmicas que se traduzem no que PLOEG (1994) define diferentes estilos de agricultura ${ }^{2}$. Esses estilos de agricultura representam a diversidade de padrões técnicos e culturais, e de diferentes relações com o mercado no interior de cada núcleo (município), e definem a diversificação da agricultura familiar revelando o interior da Rede Xique Xique. Como consta a partir do próximo item, a dinâmica regional em andamento pela Rede Xique Xique passa a ser presenciada

2 Para Ploeg (1994), o estilo de agricultura (styles of farming) é um complexo, ou um conjunto integrado de noções, normas, conhecimentos, experiências, etc., apreendido ao longo do tempo por grupos de agricultores de uma região especifica, e que descreve o modo com que a práxis da agricultura é levada adiante. quando da análise das informações de pesquisa junto às atividades de comercialização solidária desenvolvidas por agricultores familiares.

\section{REDE XIQUE XIQUE}

Analisando a Rede Xique Xique, percebe-se que as formas de organização da produção e do trabalho que as constitui são imprescindíveis para acionar sua estrutura de funcionamento. Conforme mostra a figura 1, sua constituição é definida por núcleos (municípios em que atua), por suas feiras agroecológicas locais da agricultura familiar (as quais representam conceitualmente a essência da economia solidária) e a Associação de Comercialização Solidária (esta o ambiente de comercialização em Mossoró), e pelas quatro formas predominantes de organização da produção e do trabalho: unidade familiar, grupos (sendo considerados de mulheres ou mistos), associações e cooperativas.

Essas formas de organização da produção e do trabalho cumprem o papel de operacionalização da estrutura da Rede Xique Xique, sendo importantes estratégias que viabilizam a produção agroecológica conectando esta a mercados através da Economia Solidária. Esta conexão acontece através da comercialização nas feiras semanais locais dos núcleos e na Central de Comercialização em Mossoró (eixo privado), e através do acesso a políticas territoriais formadas por programas governamentais (eixo público), a exemplo do Programa de Aquisição de Alimentos (PAA) e do Programa Nacional de Alimentação Escolar (PNAE).

Foram observados, portanto, aspectos negativos, a exemplo de dificuldades enfrentadas pelos agricultores familiares (especialmente infraestrutura de produção, acompanhamento técnico, acesso a financiamento e logística de comercialização), assim como aspectos positivos tais como o potencial fantástico da produção agrícola e de agregação de valor (artesanato, polpa de frutas, mel, castanha de caju, etc.). Ao longo da pesquisa, a Rede Xique Xique apresentou uma significativa diversificação de produtos, uma infraestrutura de produção nascente e ainda frágil, uma estrutura de organização social e econômica que surge viabilizada pelas políticas públicas, etc. A cultura e a identidade das feiras locais de cada núcleo possuem suas particularidades e sua diversidade que expressam em seus produtos as características de seus sistemas locais de cultivo, ou seja, seus estilos de agricultura, segundo PLOEG (2003). As visitas e as pesquisas de campo possibilitaram uma 


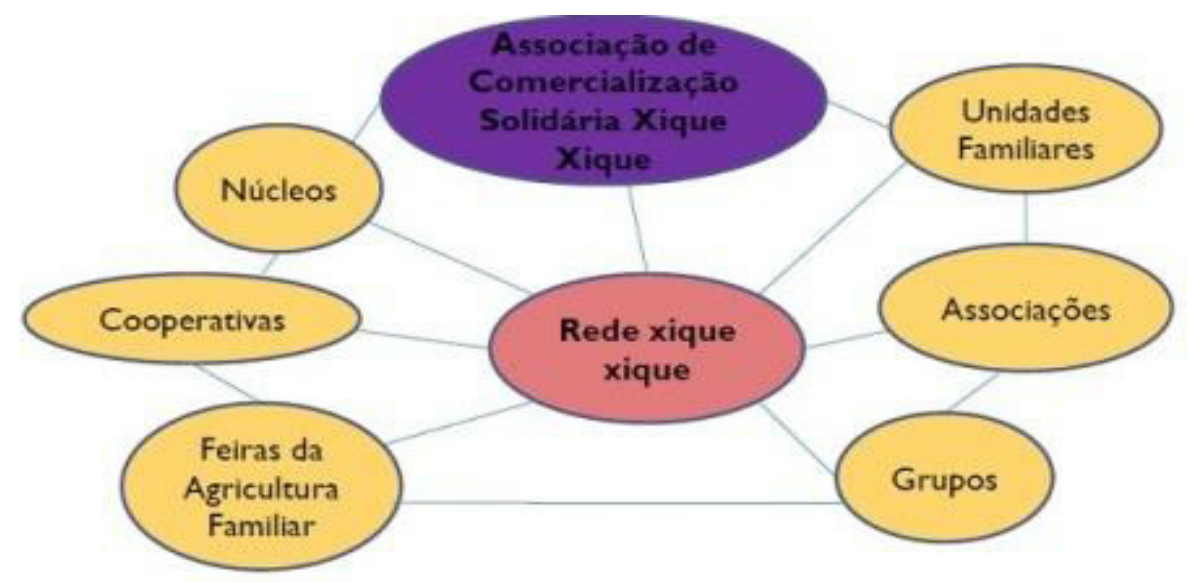

FIGURA 1: Rede Xique Xique: estrutura de organização e funcionamento.

FONTE: Rede Xique Xique, 2009.

reflexão sobre conceitos teóricos apreendidos pelos eixos temáticos discutidos no Projeto, e de como estes tem sido aplicado na realidade vivida pela Rede Xique Xique, internamente e externamente.

\section{METODOLOGIA}

O método utilizado para analisar o objeto de pesquisa proposto foi à aplicação de questionários em 21 comunidades do município Apodi/RN de atuação da Rede Xique Xique. A pesquisa vai contemplar outros 9 municípios do Rio Grande do Norte que fazem parte da Rede Xique Xique. As principais variáveis analisadas foram: o uso de insumos químicos e se pratica agroecologia ou não. Os dados foram analisados através da utilização do software SPSS versão 16. Este trabalho é fruto de pesquisa em andamento do mestrado em Ambiente, Tecnologia e Sociedade desenvolvido na UFERSA.

Desse modo, este trabalho tem como objetivo analisar o alcance da noção de agroecologia, com base no desempenho dos agricultores familiares vinculados a Rede Xique Xique em Apodi (RN). Foi analisado apenas o município de Apodi, já que é município de maior representatividade da Rede, assim, busca-se conhecer e interpretar a prática de produção dos produtos que abastecem a Rede e as feiras da agricultura familiar do município, bem como avaliar o nível da prática de agroecologia dentro deste processo. Além disso, de que maneira esse modelo supera as formas tradicionais de organização e de comercialização de modo a repercutir não apenas no aspecto econômico, mas também aspectos não econômicos, sobretudo aqueles que promovam a melhoria de vida dos que praticam esse modo de produção.

\section{ANÁLISE DOS RESULTADOS}

A Rede Xique Xique representa, além de um exemplo de economia solidária, uma experiência de diversificação que exibe um potencial expressivo de criação, expansão e fortalecimento de mercados locais e regionais por meio da produção agrícola, do artesanato e do pequeno comércio, com a ampliação de oportunidades para agricultores familiares. O caso de já ter sido desenvolvida uma organização mínima e articulação entre atores e o mercado solidário, e tal experiência encontrar-se caminhando através das feiras, faz com que a Rede Xique Xique represente um ambiente atrativo para atuações que surjam para ajudar a melhor estruturar e dinamizar suas potencialidades.

No município de Apodi, onde a pesquisa foi realizada, percebemos que na produção de alimentos ainda existe um elevado consumo de insumos externos, mesmo esses agricultores fazendo parte de uma Rede de Comercialização que tem como principio a agroecologia. Esse uso de insumos agroquímicos no município de Apodi estar sendo apresentado no Gráfico 1, que expressa a porcentagem do uso de algum tipo de insumo agroquímico, onde, cerca de $16,88 \%$, ou 27 agricultores, adotam o uso dessa prática, e $83,12 \%$ ou 142 agricultores não usam, percebemos que o resultado ainda é alto para o universo de 169 pequenos agricultores.

Pôde-se perceber ao visitar as propriedades que existe a necessidade de mostrar a esses agricultores o prejuízo ambiental, do uso de insumos químicos na produção de alimentos. Os prejuízos ambientais mais evidentes desse uso são a degradação do solo, que pode envolver salinização, alagamento, contaminação por agrotóxico, compactação, perda de fertilidade, declínio na qualidade 
Gráfico 1: Usa algum tipo de insumo agrícola químico?

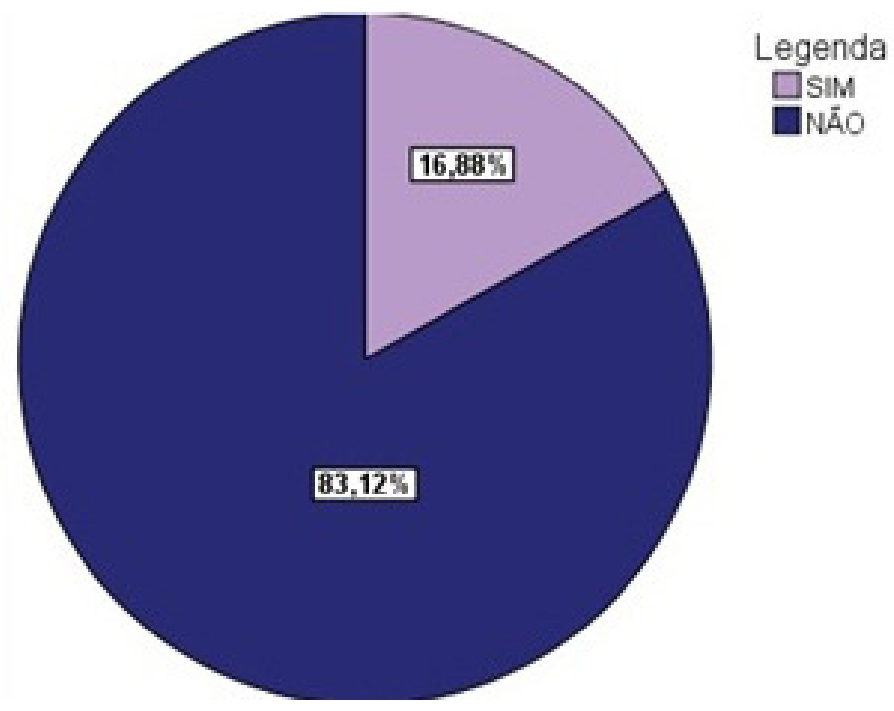

Fonte: Pesquisa de Campo, 2011.

da sua estrutura, desertificação e erosão, dentre estes problemas podemos destacar como o pior agente a erosão, uma vez destruída esta camada do solo, acaba-se o alicerce para a vida das plantas, como também a produção de alimentos e outros produtos de interesses econômicos e ambientais. A erosão dos solos afeta as águas com o aporte de sedimentos, carregados de nutrientes, provocando a eutrofização, o assoreamento dos rios, barragens e lagos, bem como a contaminação por resíduos de agroquímicos. (DIAS; PEREIRA; FUENTES. et al, 2008).

Com uso desses insumos pressupõem-se então que os alimentos produzidos dessa forma não podem ser considerados como agroecoló- gico o que vai de encontro à política da Rede Xique Xique, mesmo esta, representando uma experiência de diversificação que apresenta um potencial significativo de expansão da produção agrícola sustentável, do artesanato e do pequeno comércio, com a possibilidade de ampliação de oportunidades para agricultores familiares. No gráfico 2, estar expresso os resultados de quando foram indagados a respeito da produção ser agroecológica ou não, obteve-se um resultado razoável, onde, $79,49 \%$ ou 133 agricultores afirmam praticar a agricultura sustentável, agroecologia, e 20,51\% ou 36 agricultores asseguram que a sua produção usa algum tipo de insumo agroquímico, seja ele fertilizante, herbicida, inseticida ou fungicida.

Gráfico 2: Sua produção é Agroecológica?



Fonte: Pesquisa de Campo, 2011. 
É possível notar uma relação existente entre os dois resultados obtidos, a quantidade de agricultores que usam algum tipo de insumo agroquímico é bem próximo ao resultado dos agricultores que afirmam que a sua produção não é agroecológica, acreditando assim, que eles mesmos sendo dotados de poucos estudos e conhecimentos científicos, sabem diferenciar bem quando uma produção é agroecológica ou não, porém neste meio tem também aqueles que mesmo usando diversos insumos agroquímicos dizem ter uma produção agroecológica, assim, sabemos que para uma produção ser agroecológica, ela necessita não ter nenhum tipo de insumo externo além da relação de conservação entre produtor e meio ambiente.

\section{CONCLUSÕES}

Com base nos resultados obtidos com a aplicação dos questionários foi possível identificar que a rede Xique Xique estabeleceu um novo padrão de utilização e ocupação do solo na região do município de Apodi-RN, com a introdução de práticas agroecológicas e com uma aplicação mais próxima do conceito de desenvolvimento sustentável para a referida região. Os ganhos advindos da melhoria da qualidade de vida são perceptíveis, e geram expectativas para novos trabalhos para mensurar os impactos nos índices de desenvolvimento humano (IDH) e qualidade de vida, associados a tais atividades.

\section{REFERÊNCIAS BIBLIOGRÁFICAS}

ALTIERI, Miguel. Agroecologia: a dinâmica produtiva da agricultura sustentável. $3^{a}$ Edição -. Porto Alegre: Editora da Universidade/UFRGS, 2001.

DIAS, M. do C. O.; PEREIRA, M. C. B.; FUENTES, P. L.; et al. Manual de impactos ambientais: orientações básicas sobre aspectos ambientais de atividades produtivas. 2ed. Fortaleza: Banco do Nordeste (2008).

FRANÇA FILHO, Genauto Carvalho de e LAVILLE, Jean-Louis. A economia solidária: uma abordagem internacional. Porto Alegre: Editora da UFRGS, 2004.

GLISSMAN, S. R. Agroecologia: processos ecológicos em agricultura sustentável. Porto Alegre : Editora da Universidade/UFRGS, 2000.
NUNES, Emanoel Márcio. A Construção de Mercados para a Agricultura Familiar: processos e práticas de produção agroecológica e comercialização solidária da Rede Xique Xique. Mossoró, 2012.

NUNES, Emanoel Márcio. Reestruturação Agrícola, Instituições e Desenvolvimento Rural no Nordeste: dinâmicas regionais e a diversificação da agricultura familiar no Polo Assu-Mossoró (RN). Porto Alegre: PGDR/UFGRS, 2009 (Tese de Doutorado em Desenvolvimento Rural).

PLOEG, J. D. Van der. Camponeses e Impérios Alimentares: lutas por autonomia e sustentabilidade na era de globalização. Porto Alegre: Editora UFRGS, 2008.

SINGER, Paul. Economia Solidária: um modo de produção e distribuição. In: A Economia Solidária no Brasil: a autogestão como resposta ao desemprego. SINGER, Paul \& SOUZA, A. R. de (Orgs) São Paulo: Contexto, 2000.

SINGER, Paul. Introdução à Economia Solidária. $1^{a}$ ed.- São Paulo: Editora Fundação Perseu Abramo, 2002.

WILLIAMSON, Oliver E. (2000). The New Institutional Economics: Taking Stock, Looking Ahead. Journal of Economic Literature. Vol. XXXVIII, pp. 595-613, Sept. 